\title{
JURIDICIZAÇÃO DA HISTÓRIA E TOTALITARISMO
}

\author{
Heitor Pagliaro ${ }^{1}$ \\ Professor de Direito - Universidade Federal de Goiás \\ Doutor em Direito - Universidade de Brasília \\ heitor@heitorpagliaro.com
}

\begin{abstract}
Resumo: Este artigo problematiza os discursos políticos presentes nos preâmbulos dos Atos Institucionais da ditadura militar, como fontes históricas, para analisar as condições de possibilidade do exercício legítimo do poder político no golpe militar brasileiro, em 1964. Essa abordagem é feita a partir dos conceitos de violência fundadora e violência mantenedora, em Força de Lei, de Jacques Derrida. O objetivo é compreender, em termos filosófico-políticos, como se deu o movimento de transição política do golpe militar brasileiro, considerando a questão da legitimidade do governo em um contexto de revolução totalitarista, para pensar sobre como a vinculação da política a questões de legalidade pode conduzir, em certo sentido, a uma juridicização da história.
\end{abstract}

Palavras-chave: direito; história; totalitarismo.

\section{JURIDICALIZATION OF HISTORY AND TOTALITARIANISM}

Abstract: This article problematizes the political discourses in the Institutional Acts of the military dictatorship, considered as historical sources, in order to analyze the conditions of possibility of the political power of the Brazilian government during the military coup in 1964 . I conduct this analysis considering the notions of law-making violence and law-preserving violence on Jacques Derrida's Force of Law. The aim of this work is to understand, in political philosophical terms, the political transitional movement during the military coup in Brazil, considering the question of legitimacy of the government in a context of totalitarian revolution, in order to analyze how thinking politics as a matter of legality could lead, in some sense, to a juridicalization of history.

Keywords: law; history; totalitarianism.

\footnotetext{
${ }^{1}$ Currículo Lattes: http://lattes.cnpq.br/7702958081106244; ORCID: https://orcid.org/0000-0001-6431-930X.
} 
O totalitarismo é um termo político empregado para designar uma forma e não um conteúdo. Isso significa, por exemplo, que quando se atribui o predicado totalitário a uma decisão política, não se faz referência ao conteúdo desta decisão, mas à sua forma. Não é um predicado valorativo do conteúdo, mas descritivo da forma, ou seja, se uma pessoa atribuísse o caráter totalitário a um regime político, isso não forneceria elementos suficientes para se fazer um juízo de valor sobre as decisões desse regime quanto ao seu conteúdo. O mesmo ocorre com o termo democracia, pois democraticamente podem-se tomar decisões excelentes e também decisões terríveis. Isso significa dizer, por exemplo, que uma mesma decisão política poderia ser tomada tanto democraticamente quanto totalitariamente. O que distingue essas duas coisas tem a ver com o modo da tomada de decisão.

Como o termo é usado quase sempre para caracterizar uma realidade política (um regime, um ato, um governo, um Estado), é preciso entender o que, em linhas gerais, se quer dizer quando se rotula algo de totalitário. Trata-se de uma realidade política na qual o Estado é total:

o Estado não representa um partido, o Estado representa a coletividade nacional, compreende tudo, supera a todos, protege todos e se coloca contra qualquer um que atente contra a sua imprescritível soberania (MUSSOLINI, 1942, p. 106, tradução minha). ${ }^{2}$

As palavras acima, do próprio Benito Mussolini, em um discurso em 1925, em Milão, descrevem esse caráter da totalidade do Estado. O totalitarismo adota a ideia de um Estado total, que está presente em todo lugar, "compreende tudo", isto é, controla todos os aspectos da vida. Como resumiu Piraino: "a essência do fascismo é representada pelo Estado fascista" (PIRAINO, 2014, p. 9, tradução minha). ${ }^{3}$ Essa totalidade guarda alguma similitude com a estrutura política do antigo regime francês, tal como descrita por Claude Lefort:

$\mathrm{O}$ antigo regime era composto por um número infinito de pequenos corpos que permitiam a identificação dos indivíduos. Todos esses pequenos corpos considerados conjuntamente compunham um grande corpo imaginário, corporificado na figura concreta do rei, que garantia a sua integridade. A revolução democrática, por muito tempo contida, vem à tona quando o corpo do rei foi destruído, quando o corpo

\footnotetext{
2 "Lo Stato non rappresenta un partito, lo Stato rappresenta la collettività nazionale, comprende tutto, supera tutti, protegge tutti e si mette contro chiunque attenti alla sua imprescrittibile sovranità".

3 "L'essenza del fascismo è rappresentata dallo stato fascista".
} 
político foi decapitado e quando, ao mesmo tempo, a corporeidade da sociedade foi dissolvida (LEFORT, 1986, p. 303, tradução minha). ${ }^{4}$

Claude Lefort explica que assim como o rei corporifica o todo no antigo regime, o governante no totalitarismo também cumpre essa função de conferir unidade à sociedade (no socialismo soviético, por exemplo) e ao Estado (no caso do nazifascismo). Como se nota, diferentemente do liberalismo - cujo epicentro conceitual é o indivíduo e sua liberdade -, a palavra de ordem do totalitarismo e do antigo regime é o todo (simbolizado ora pelo Estado, ora pela sociedade) - e a sua proteção. Isso fica claro nas próprias palavras de Mussolini, em outro discurso em Milão, em 1922, no qual enfatiza a supremacia do Estado:

a ideia central no nosso pensamento é o Estado; o Estado é a organização política e jurídica da sociedade nacional e se expressa em uma série de instituições de várias ordens. A nossa fórmula é essa: tudo no Estado, nada fora do Estado e nada contra o Estado (MUSSOLINI, 1934, p. 162, tradução minha). ${ }^{5}$

As tentativas de definição do totalitarismo comumente fazem referências à democracia, tendo em vista que aquele se manifesta no século XX como uma alternativa à (e a partir das falhas da) democracia liberal.

É importante ponderar que a preocupação com os conceitos tem fim teórico, mas essa perspectiva teórica é essencial para a atividade historiográfica, para a qual os conceitos cumprem um papel fundamental, enquanto ideias que contribuem para a descrição e análise crítica de fenômenos políticos (no caso da história política).

O termo totalitarismo foi bastante difundido durante a Guerra Fria, em um sentido pejorativo, para designar um tipo de regime político que abarcava tanto o nazifascismo europeu quanto o comunismo soviético. Segundo o historiador Richard Pipes, a difusão do termo foi uma estratégia retórica de manipulação da opinião pública contra a União Soviética, no pósguerra: “diz-se que a concepção de ‘totalitarismo' foi concebida como uma arma da Guerra

\footnotetext{
4 "The ancien régime was made up of an infinite number of small bodies which gave individuals their distinctive marks. And these small bodies fitted together within a great imaginary body for which the body of the king provided the model and the guarantee of its integrity. The democratic revolution, for so long subterranean, burst out when the body of the king was destroyed, when the body politic was decapitated and when, at the same time, the corporeality of the social was dissolved".

5 "L'idea centrale del nostro movimento è lo Stato; lo Stato è l'organizzazione politica e giuridica delle società nazionali e si estrinseca in una serie di istituzioni di vario ordine. La nostra formula è questa: tutto nello Stato, niente al di fuori dello Stato, nulla contro lo Stato".
} 
Fria: a ligação do comunismo com o nazismo ajudou a opinião pública contra a União Soviética” (PIPES, 1995, p. 243, tradução minha). ${ }^{6}$ O valor semântico negativo da palavra já existia desde 1923, quando o termo foi cunhado por Giovanni Amendola, um jornalista italiano crítico do governo do presidente do Conselho de Ministros do Reino da Itália no período 19221943, Benito Mussolini.

Donattela Pacelli (2013) explicou que “Amendola introduz a expressão 'espírito totalitário' nos anos vinte, com a finalidade de explicar a confluência de fatores que estavam deflagrando a mudança radical da sociedade italiana". Na década seguinte, Guglielmo Ferrero resgata o termo totalitarismo, fazendo uma genealogia histórica do fenômeno, focando nos aspectos psicológicos que conduzem à escolha do fascismo como modelo de governo ideal, chegando a definir totalitarismo como a dominação exclusiva de uma só doutrina, grupo e partido, sem controle e limites (PACELLI, 2013). Um fato importante é que o governo de Mussolini era descrito por ele próprio como fascista (em conotação positiva), ao passo que Amendola o descrevia como totalitarista (em conotação negativa). Portanto, ambos os conceitos surgiram com uma carga semântica valorativa.

As relações entre os regimes totalitaristas do século $\mathrm{XX}$ vão além da sua mera contemporaneidade. É possível apontar diversas ligações entre eles. Apenas como um exemplo, pode-se mencionar uma das conexões entre o fascismo italiano e o nazismo alemão, evidenciada em uma passagem do diário (publicado post mortem) do genro de Mussolini e diplomata, Gian Galeazzo Ciano, escrito em 1941, citando uma fala de Mussolini:

\begin{abstract}
A Europa será dominada pela Alemanha. Os Estados conquistados serão verdadeiras colônias. Os Estados associados serão províncias confederadas. Entre estas, a mais importante é a Itália. É necessário aceitar esse estado de coisas, porque qualquer tentativa de reação resultaria na desclassificação de província confederada àquela bem pior de colônia (CIANO, 1963, p. 76, tradução minha). ${ }^{7}$
\end{abstract}

A fala de Mussolini acima, relatada por seu genro, mostra com clareza a relação entre o fascismo italiano e o nazismo alemão, bem como sublinha o poderio alemão na segunda guerra.

\footnotetext{
6 'The concept of 'totalitarism' is said to have been devised as a weapon of the Cold War: linking comunism with nazism helped turn public opinion against the Soviet Union".

7 “L'Europa sarà dominata dalla Germania. Gli Stati vinti saranno vere e proprie colonie. Gli stati associati saranno provincie confederate. Tra queste, la più importante è l'Italia. Bisogna accettare questa stato di cose perché ogni tentativo di reazione ci farebbe declassare dalla condizione di provincia confederata a quella ben peggiore di colonia".
} 
O pangermanismo, associado à expansão territorial, era a característica que estava na base no totalitarismo alemão.

Costuma-se dizer que os totalitarismos recebem nomes diferentes de acordo com o contexto no qual se manifestam. Na América Latina do século XX: ditadura. Na Itália de Mussolini: fascismo: Na Alemanha de Hitler: nazismo. Na União Soviética de Stalin: stalinismo ou comunismo. É claro que há diferenças entre esses regimes, pois cada um se deu em uma época particular, em um contexto particular, em uma determinada cultura e por motivos próprios. Porém, pode-se dizer que todos são, em maior ou menor grau, expressões de ideais centrais do totalitarismo. É interessante observar que todas essas experiências políticas aconteceram no "século breve" - para usar o termo de Eric Hobsbawm (1995), embora este mesmo tenha afirmado que o termo é de Ivan Berend.

O fascismo de Mussolini foi aliado do nazismo de Hitler, que por sua vez foi adversário do stalinismo soviético. A própria ditadura Vargas, do Estado Novo, era simpática aos ideais italianos de então e, por sua vez, a ditadura militar brasileira era declaradamente anticomunista, sendo que a "revolução vitoriosa" foi entendida pelos seus próprios autores como um ato de defesa contra a ameaça comunista - em pleno contexto de Guerra Fria.

Ainda que haja, em maior ou menor grau, similitudes entre, por exemplo, o fascismo italiano, o nazismo alemão, o comunismo soviético, o Estado Novo de Getúlio Vargas, a ditadura militar brasileira e as demais ditaduras latino-americanas, a comparação desses fenômenos - considerados enquanto expressões totalitaristas - não é pacífica entre os historiadores. Essa generalização pode ser até atrativa, por facilitar a descrição de diversos fenômenos políticos do século XX. Todavia, quanto mais aberto e amplo se torna um conceito político, mais ele perde seu poder definidor e descritivo, tornando-se quase um recurso retórico que se presta mais à persuasão em debates eloquentes, do que ao rigoroso trabalho historiográfico.

A título de exemplo, um dos problemas em denominar o Estado Novo de fascista é que aquele tinha uma pretensão modernizadora, enquanto o fascismo, diferentemente, considera o passado como uma referência política. Como explicou João Fábio Bertonha: “O encanto fascista pelo passado é, com certeza, um traço importante na sua ideologia e que o faz diferir de ditaduras modernizantes, como a do Estado Novo do Brasil" (BERTONHA, 2015, p. 206). Por outro lado, o fascismo italiano adota uma posição contrária ao comunismo, ao socialismo 
e à democracia, propondo uma nova ordem e essas características guardam similitude com a ditadura militar brasileira.

O totalitarismo, segundo Lefort, surge a partir da democracia e propõe uma unidade à soberania, que é justamente o que, segundo o autor, falta na democracia. Esta postula a soberania popular, isto é, o poder do povo, mas essa ideia de povo precisa ser constantemente atualizada, por ser demasiadamente efêmera, fluída e constantemente variável. A ausência do rei, que corporifica a unidade do todo, se perde na democracia e encontra no totalitarismo a oportunidade de ser retomada - mas em outra forma. Por isso as noções de unidade, povo-uno, um só partido e uma só ideia são tão caras às experiências totalitárias, assim como a eleição de inimigos bem definidos (judeus, imigrantes, comunistas, entre outros, dependendo de qual experiência política se faz referência). Essas respostas simples e unas, oferecidas pelos governos totalitários, buscam superar a falta de unidade da democracia liberal. Em todo caso, o totalitarismo propõe a fundação de uma nova ordem política e social, por meio de uma radical remodelação do poder político exercido pelo Estado.

É precisamente sobre essa transição de ordem que se debruça este artigo. A transição política marcada pelo golpe militar de 1964, no Brasil, promoveu o rompimento de uma ordem e o estabelecimento de outra, por meio de uma revolução. A consolidação do novo status quo político se deu por meio do direito, isto é, o governo militar criou legislações sem precedentes, de natureza jurídica muito particular: fala-se aqui dos famosos atos institucionais e também dos menos conhecidos atos complementares. Portanto, essa transição política foi juridicizada e esse processo de juridicização do estabelecimento da nova ordem deixou como legado documentos oficiais - legislações - que podem ser considerados, hoje, como fontes históricas. Este artigo analisa essas fontes históricas, a partir da contextualização de suas elaborações, discutindo o papel que tiveram no âmbito da transição política ocorrida no Brasil naquele período.

A juridicização da história ${ }^{8}$ - da qual faz parte o fenômeno mais específico da tribunalização da história - pode ser pensada no contexto brasileiro da década de sessenta do

\footnotetext{
${ }^{8}$ Esse termo já foi empregado por Judith Butler (1997, p. 50) em Politics of the Performative. Como comentou Fortier, Butler pensa que "a história, por ser temporária, não é 'processável'. O que foi colocado em julgamento, então, não foram os 'fatos' da história, mas os 'sujeitos' da história. Como Butler escreve, 'a juridicização da história é alcançada precisamente através da busca de pessoas a serem processadas, que podem ser responsabilizadas, resolvendo, assim, temporariamente, o problema fundamental da incapacidade de a história ser processada"" (FORTIER, Anne-Marie. Multiculturalism and the new face of Britain. Department of Sociology, Lancaster University, p. 4, tradução minha. Disponível em: http:/www.comp.lancs.ac.uk/sociology/papers/ Fortier-Multiculturalism.pdf. "History is, by virtue of its temporality, unprosecutable. What was put to trial, then,
} 
século $\mathrm{XX}$, a partir da hipótese segundo a qual o jurídico figurou como ferramenta da construção da nova ordem, isto é, como uma ferramenta que, em certo sentido, contribuiu para a definição dos rumos políticos que a história brasileira tomou após 1964. Porém, o jurídico figura também como uma fonte histórica, fornecendo elementos para compreender como se deu a transição para o governo militar. Contudo, as legislações não são documentos meramente técnicos e podem conter discursos ideológicos (explícitos ou implícitos) e até a assunção ou a rejeição (subjacente ou aberta) de determinados arquétipos de sujeito, ideias ou valores políticos. Sendo assim, o emprego de legislações como fontes históricas deve ser problematizado em relação ao contexto político no qual foram elaboradas. É exatamente a isso que se propõe o presente artigo.

Os Atos Institucionais foram uma figura jurídica peculiar no governo militar brasileiro. Eles promoviam modificações gerais no ordenamento jurídico, chegando ao ponto de alterar a constituição do país. Eram atos legislativos unilaterais, isto é, elaborados e publicados exclusivamente pelo chefe do poder executivo, sem necessidade de aprovação pelo Congresso Nacional. Esses documentos legais continham preâmbulos, que eram textos introdutórios recheados de discursos - verdadeiras cartas revolucionárias voltadas não só à consolidação da nova ordem, mas sobretudo à sua justificativa e definiçãa. Isso é nítido no Ato Institucional I:

É indispensável fixar o conceito do movimento civil e militar que acaba de abrir ao Brasil uma nova perspectiva sobre o seu futuro. O que houve e continuará a haver neste momento, não só no espírito e no comportamento das classes armadas, como na opinião pública nacional, é uma autêntica revolução (BRASIL, 1964).

Como se nota, houve uma séria preocupação com a juridicização do discurso de transição política, pois não apenas justificaram a nova ordem, mas justificaram a própria necessidade de definir a nova ordem. Além disso, nota-se o caráter prospectivo do discurso, quando se emprega as palavras "futuro" e "nova", para se referir à perspectiva política que se iniciava ali - estava presente de certo modo, a ideia de rompimento com o velho, identificado ou rotulado aqui como os "ideais comunistas". Esses atos impunham a pauta ideológica não só do novo governo, mas do novo "Estado", tendo em vista que suas disposições, ao alterarem

was no so much the 'fatcs' os history, but, rather, the subjects of history. As Butler writes, 'the juridicalization of history $[. .$.$] is achieved precisely through the search for subjects to prosecute who might be held accountable and,$ hence, temporarily resolve the problem of a fundamentally unprosecutable history"". 
tanto a constituição quanto todas as disposições anteriores divergentes, fundavam uma nova estrutura jurídico-política do Estado.

O preâmbulo do Ato Institucional $1 \mathrm{fez}$ com que a postura anticomunista do governo militar se juridicizasse, isto é, passasse de um postulado político para uma disposição legal. É possível notar duas questões: a expressa posição contrária ao comunismo, atribuído ao então governo deposto, e a descrição do ato político como revolução. Conforme o texto da norma:

\begin{abstract}
Para demonstrar que não pretendemos radicalizar o processo revolucionário, decidimos manter a Constituição de 1946, limitando-nos a modifica-la, apenas, na parte relativa aos poderes do Presidente da República, a fim de que este possa cumprir a missão de restaurar no Brasil a ordem econômica e financeira e tomar as urgentes medidas destinadas a drenar o bolsão comunista, cuja purulência já se havia infiltrado não só na cúpula do governo como nas suas dependências administrativas (BRASIL, 1964).
\end{abstract}

É importante observar que os militares intitularam o ato político como revolução vitoriosa, ou seja, como uma revolução que venceu, que tomou o poder. Além disso, como revolução que se investe no poder constituinte. Nesse ponto, é importante fazer algumas observações. A primeira é que se trata de uma autoinvestidura, isto é, um poder autoproclamado. Na linguagem constitucionalista isso se traduziria em um poder constituinte originário, que não deriva de um anterior - ou, conforme o próprio texto do preâmbulo: uma revolução que "se legitima por si mesma" (BRASIL, 1964). É uma característica típica das revoluções. A nova ordem expressa sua novidade em dois sentidos: ela é diferente da antiga em termos de conteúdo e também é erigida institucionalmente de modo originário, isto é, sem seguir as exigências formais anteriores para alteração constitucional. A segunda é que a revolução se autodeclara vitoriosa.

O imaginário conceitual do discurso do Ato Institucional 1 mantém certas ideias que são próprias da democracia. Dessa forma, o autoritarismo do novo regime promove uma ruptura institucional, mas mantém algumas raízes com a tradição (se não de fato, ao menos em nível de discurso jurídico). O preâmbulo do Ato Institucional 1 mantém a ideia de soberania popular como fundamento do poder legítimo, a despeito de definir arbitrariamente quem (e como) representaria o "povo". A linguagem constitucional de poder constituinte é mantida. Essa intenção de conservar alguns aspectos da tradição é expressa quando se fala em manter a constituição e o congresso nacional: 
Para demonstrar que não pretendemos radicalizar o processo revolucionário, decidimos manter a Constituição de 1946. (...) Para reduzir mais ainda os plenos poderes de que se acha investida a revolução vitoriosa, resolvemos, igualmente, manter o Congresso Nacional (BRASIL, 1964).

Se a manutenção ou não do congresso nacional passou a ser uma deliberação do poder executivo, isso demonstra a subordinação do legislativo ao executivo, que se intitula investido em "plenos poderes". Sabe-se que alguns anos depois o Ato Institucional 5 (AI-5) criou poderes para o executivo fechar o congresso nacional. ${ }^{9}$ No mesmo dia da publicação do AI-5, também foi editado o Ato Complementar $38^{10}$, que, exercendo os poderes recém criados pelo AI-5, efetivamente fechou ${ }^{11} \mathrm{o}$ congresso nacional por mais de dez meses.

É claro que a tomada do poder foi realizada através de atos que, nas datas em que foram realizados, eram considerados ilegais (pela ordem jurídica pré-revolucionária). Portanto, o novo governo, instituído ilegalmente, precisou "regularizar" a sua situação jurídica e o fez modificando as leis para que se tornasse um governo legítimo (conforme à lei), de acordo com a nova legislação, a despeito de seus atos de investidura no poder terem violado o direito então vigente.

Assim, o novo governo não permaneceu à margem da antiga ordem por muito tempo, pois no mesmo ano de sua autoinvestidura alterou a ordem, de modo a se tornar um governo legítimo - tomando-se como referência de legitimidade legal a nova ordem instaurada. Portanto, os principais atos do governo militar foram não só políticos, conforme os ideais da "revolução vitoriosa”, mas também jurídicos.

A associação entre governo legal e poder legítimo é clássica, conforme lembrou Arendt em As Origens do Totalitarismo, onde ela afirma que as experiências dos governos totalitários desafiam a questão da legalidade:

\footnotetext{
9 “Art. $2^{\circ}$ - O Presidente da República poderá decretar o recesso do Congresso Nacional, das Assembleias Legislativas e das Câmaras de Vereadores, por Ato Complementar, em estado de sitio ou fora dele, só voltando os mesmos a funcionar quando convocados pelo Presidente da República.

$\S 1^{\circ}$ - Decretado o recesso parlamentar, o Poder Executivo correspondente fica autorizado a legislar em todas as matérias e exercer as atribuições previstas nas Constituições ou na Lei Orgânica dos Municípios".

10 “Art. $1^{\circ}$ Nos têrmos do art. $2^{\circ}$ e seus parágrafos, do Ato Institucional no 5, de 13 de dezembro de 1968, fica decretado o recesso do Congresso Nacional, a partir desta data".

${ }^{11} \mathrm{O}$ verbo empregado no documento legal foi suspender (as atividades do congresso nacional), com os mesmos efeitos práticos.
} 
o totalitarismo nos coloca diante de uma espécie totalmente diferente de governo. É verdade que desafia todas as leis positivas, mesmo ao ponto de desafiar aquelas que ele próprio estabeleceu (ARENDT, 1958 p. 461, tradução minha). ${ }^{12}$

Como ficaria a legitimidade dos atos de uma revolução inexitosa? Nesse caso, seus atos permanecem ilegais e ilegítimos conforme a ordem posta, que a repeliu e a destruiu. Porém, continua legítima na ordem hipotética, que existia "na imaginação" (nos ideais) das pessoas que promoveram a revolução, então sua legitimidade seguirá existindo em abstrato, ou seja, nas ideias da revolução, na ordem porvindoura, potencial, mas que não chegou a se realizar. Por outro lado, quando uma revolução obtém êxito (e toma o poder), ela modifica a ordem prérevolucionária, fazendo com que passe a existir uma espécie de legitimidade retroativa, no sentido de que a nova ordem (política e jurídica) legitima, ou seja, reconhece como corretos, os atos revolucionários, que em relação à ordem anterior, eram marginais e ilícitos. Assim, a revolução vitoriosa inclui a posteriori os atos revolucionários dentro da nova ordem, legitimando-os retroativamente. O filósofo francês Jacques Derrida explicou isso em Força de Lei. Ao tratar da legitimidade da revolução sem êxito ou ainda não vitoriosa, afirmou:

o sujeito suposto desse performativo não estaria mais diante da lei, ou melhor, ele estaria diante de uma lei ainda indeterminada, diante da lei como uma lei ainda inexistente, uma lei ainda por vir, ainda à frente e devendo vir (DERRIDA, 2007, p. 84).

Derrida explicou ainda que a autorização dos atos revolucionários depende somente de quem os produz, não havendo vinculação a outra lei ou outra ordem, sendo uma espécie de ato juridicamente autônomo. Assim, Derrida considera que a violência fundadora - aquela que funda uma nova ordem - é sempre autorizada por ditames jurídicos e políticos porvindouros. Uma vez exitosa, os que antes eram revolucionários (oposição) passam a ser a situação e instauram a nova ordem, de tal modo que a violência fundadora passa a dar lugar à violência mantenedora, uma vez que o esforço agora é para manter um novo estado de coisas e não mais romper. $\mathrm{O}$ autor sustentou que a possibilidade de crítica dos dois tipos de violência é paradoxal, pois ao mesmo tempo em que a violência fundadora parece ser mais fácil de ser criticada, por não ser justificada por nenhuma legalidade preexistente, ela é, por isso mesmo, mais difícil de

\footnotetext{
12 "Totalitarian rule confronts us with a totally different kind of government. It defies, it is true, all positive laws, even to the extreme of defying those which it has itself established".
} 
ser criticada, pois não se pode confrontá-la diante de uma instituição preexistente, já que ela é alheia à ordem que visa destruir. Segundo Derrida:

Uma revolução bem-sucedida, a fundação bem-sucedida, produzirá, a posteriori, aquilo que ela estava destinada de antemão a produzir, isto é, modelos interpretativos próprios para serem lidos retroativamente, para dar sentido, necessidade e sobretudo legitimidade à violência fundadora que produziu (DERRIDA, 2007, p. 84).

Esse pensamento promoveu a desconstrução das ideias tradicionais entre política e direito, ao evidenciar que atos políticos podem conferir legitimidade jurídica a si próprios. Glendinning explica que a questão principal em Derrida não é "a filosófica sobre os fundamentos da autoridade legal e a possibilidade da justiça, mas a questão política sobre a violência de uma autoridade legalmente constituída (GLENDINNING, 2016, p. 189, tradução minha)". ${ }^{13}$

Esse é o grande ponto da filosofia jurídica de Derrida, que contribui para a compreensão dos regimes totalitaristas do "breve século", especificamente da ditadura militar brasileira, pois ela promoveu essa legitimação jurídica a posteriori, ou seja, o novo regime legislou com o objetivo de dar conformidade jurídica às suas ações políticas que ao tempo dos atos de tomada de poder eram ilegítimos conforme a antiga ordem. Thiago Soares de França contribuiu com a interpretação de Derrida, nesse aspecto, quando afirmou: “a desconstrução do direito (...) é igualmente a desconstrução das noções de autoridade, soberania, lei e demais conceitos clássicos da tradição política" (FRANÇA, 2012, p. 220).

Essa ideia de que um ato político pode dar legitimidade a si mesmo (como ocorre nas revoluções exitosas), remete ao célebre trilema de Münchhausen, também chamado de trilema de Agripa. Segundo este, adotando um pensamento cético, toda tentativa de provar algo incorre necessariamente em uma das três estratégias (todas absurdas): a regressão infinita, a escolha arbitrária e a petição de princípio.

Conforme a primeira, para se provar que algo é verdadeiro, é preciso recorrer a outro fundamento superior e anterior, que dá validade ao que se quer provar - e sempre há a necessidade de recorrer a outro fundamento, em um processo lógico infinito, considerado absurdo, pois nunca se chega a algum lugar.

\footnotetext{
13 "The question is not the philosophical one about the foundations of legal authority and the possibility of justice, but the political one about the violence of existing legal authority".
} 
Conforme a segunda, em determinado momento da cadeia lógica há um corte arbitrário, como explicou Alexandre Araújo Costa: "para cortar a cadeia infinita, é preciso um corte arbitrário, com a apresentação de uma norma válida em si mesma" (COSTA, 2009, p. 9), que dá validade às demais. Esta seria a estratégia, por exemplo, da norma fundamental, na Teoria Pura do Direito de Hans Kelsen.

A terceira estratégia estabelece uma proposição que simplesmente considera que " $\mathrm{X}$ " é válido, logo, tudo que não é "X" não é válido. Trata-se de um argumento circular, como exemplificou Alexandre Araújo Costa, mencionando o princípio constitucional brasileiro atual, segundo o qual, no artigo $1^{\circ}$, parágrafo único: "todo o poder emana do povo" (BRASIL, 1988). Isso é válido porque está na Constituição e esta, por sua vez, é considerada válida por emanar do povo. Isso significa que a constituição é válida por que ela mesmo se atribuiu uma validade, através desse exercício retórico. É como se João, um rei, dissesse que governa porque todo rei é escolhido de Deus, logo, se ele governa, é porque é escolhido de Deus e por isso deve governar. Enfim, ele governa porque governa. Trata-se de um modo de pensar circular, no qual, no fim das contas, algo é verdadeiro, válido ou legítimo por uma espécie de argumento de autoridade que estabelece os próprios critérios.

As revoluções exitosas, conforme pensou Derrida, estabelecem a própria legitimidade, nos moldes da terceira estratégia de pensamento circular, criando normas que atribuem ao próprio regime um status de legalidade. O poder de legislar, criando a própria legalidade, vem do fato de se atribuírem o poder de legislar e o que foi legislado confere ao novo governo o poder de governar e de legislar, em um círculo logicamente absurdo. Pensando assim, a ditadura militar brasileira, que teve seu início através de uma revolução contra o status quo ante, é uma espécie de autocracia, isto é, um poder independente e autônomo que simplesmente é exercido de fato. Qualquer máscara jurídica que criada não passaria de uma retórica para encobrir um poder ilegítimo ou que se legitima a si mesmo - conforme o argumento circular do Trilema de Münchhausen. Pensando assim, os discursos jurídicos dos preâmbulos dos Atos Institucionais são uma ideologia, no sentido marxista: um discurso para encobrir a própria ilegitimidade.

Nota-se, portanto, que o direito é empregado pelos regimes totalitários como ferramenta de criação de uma legitimidade autoritária, contribuindo para o direcionamento dos rumos da história política de um país. Poder-se-ia falar, aqui, de uma juridicização da história. Ao mesmo tempo, os documentos legais acabam tornando-se fontes para a pesquisa historiográfica, mas 
fontes que devem ser problematizadas conforme os movimentos políticos da época na qual foram criadas, para que possam, em algum grau, contribuir para a compreensão de como se deram os discursos de legitimidade nos períodos de transição política revolucionária, como foi o caso da história brasileira em 1964.

Essa relação entre direito e totalitarismo foi analisada também por Hannah Arendt, que ressaltou seu caráter histórico, frisando a condição de movimento das concepções de lei nazista e bolchevista. A primeira, com a ideia de lei natural - na qual subjaz a noção darwinista de evolução natural -, e a segunda, com a concepção de lei histórica - na qual está presente a noção da sociedade como um gigantesco movimento histórico:

na interpretação do totalitarismo, todas as leis são leis de movimento. Embora os nazistas falassem de lei da natureza e os bolchevistas falem da lei da história, natureza e história deixam de ser a força estabilizadora da autoridade para as ações dos homens mortais, elas próprias se tornam movimentos (ARENDT, 1958, p. 463, tradução minha). ${ }^{14}$

Por fim, resta ponderar que os documentos legais, especialmente os preâmbulos dos Atos Institucionais do governo militar brasileiro, são fontes históricas internas ao objeto de estudo, isto é, contêm discursos que são produzidos pelos próprios autores da "revolução vitoriosa" - diferentemente de fontes externas, que seriam narrativas de terceiros sobre o objeto de estudo. O recurso aos Atos Institucionais como fontes de informação histórica não significa uma análise acrítica de seu conteúdo, mas precisamente a compreensão de como o governo militar empregou o direito como ferramenta política de legitimação autoritária de seus atos.

Isso não significa resumir a história política da ditadura militar brasileira a uma análise da legalidade de seu governo, isto é, a pergunta não é quem tem o direito de governar, mas a atenção ao âmbito jurídico significa, aqui, uma preocupação sobre como a questão da legitimidade do poder político foi expressa, pelos autores da ditadura militar, em termos jurídicos. Pelo que foi pensado, compreende-se que a história política da transição do poder em 1964 não pode ser completamente entendida sem a problematização dos discursos legais presentes nos documentos legislativos dos primeiros anos do governo militar.

\footnotetext{
14 "In the interpretation of totalitarianism, all laws have become laws of movement. When the Nazis talked about the law of nature or when the Bolsheviks talk about the law of history, neither nature nor history is any longer the stabilizing source of authority for the actions of mortal men; they are movements in themselves".
} 


\section{Referências bibliográficas:}

ARENDT, Hannah. The Origins of Totalitarianism. Nova Iorque: Meridian Books, 1958.

BRASIL. Ato Institucional n. 1, de 09 de abril de 1964. Brasília: Congresso Nacional.

BRASIL. Ato Institucional n. 5, de 13 de dezembro de 1968. Brasília: Congresso Nacional.

BRASIL. Ato Complementar n. 38, de 13 de dezembro de 1968. Brasília: Congresso Nacional.

BRASIL. Constituição da República Federativa do Brasil de 1988. Brasília: Congresso Nacional.

BERTONHA, João Fábio. Sobre Fascismos e Ditaduras: a herança fascista na formatação dos regimes militares do Brasil, Argentina e Chile. Revista de História Comparada. Rio de Janeiro, v. 9 , n. 1, p. 203-231, 2015.

BUTLER, Judith. Politics of the Performative. Nova Iorque; Londres: Routledge, 1997.

CIANO, Galeazzo. Diari. Vol. II (1939-1943). Milano: Rizzoli, 1963.-

COSTA, Alexandre Araújo. Curso de Filosofia do Direito. 2009. Disponível em < http://www.arcos.org.br/artigos/curso-de-filosofia-do-direito/>, acesso em 19/05/2020.

DERRIDA, Jacques. Força de Lei. Trad. Leyla Perrone-Moisés. São Paulo: Martins Fontes, 2007.

FORTIER, Anne-Marie. Multiculturalism and the new face of Britain. Department of Sociology, Lancaster University. Disponível em <http://www.comp.lancs.ac.uk/sociology /papers/Fortier-Multiculturalism.pdf>. Acesso em: 21/05/2020.

FRANÇA, Thiago Soares de. A Justiça como Desconstrução do Direito no Pensamento de Jacques Derrida. Ítaca, n. 19. Rio de Janeiro: UFRJ, 2012.

GLENDINNING, Simon. Derrida and the Philosophy of Law and Justice. In: Law Critique, v. 27, 2016, p. 187-203 (DOI: 10.1007/s10978-016-9183-2).

HOBSBAWM, Eric. The Age of Extremes: the short twentieth century 1914-1991. Londres: Abacus, 1995.

MUSSOLINI, Benito. Scritti e Discorsi de Benito Mussolini. Vol. 5. Milão: Ulrico Hoepli, 1934.

PACELLI, Donatella. Il Totalitarismo come “crisi per eccesso”. Sociologia, n. 1, 2013.

PIPES, Richard. Russia under the Bolshevik Regime. Nova Iorque: Old Books, 1995. 
PIRAINO, Marco. l'Essenza Dottrinale del Fascismo: lo Stato etico fascista come realtà morale, politica ed economica unitaria nella riflessione dei teorici del Regime. La Razón Histórica. n. 28, 2014. 